\title{
Artificial Intelligence as a Tool for Decision Making: A Perspective from the Central Bank of Nigeria
}

\author{
Umar Abbas Ibrahim, $\mathbf{P h D}^{\mathbf{1}^{*}}$, Chinyere Jane Nwobilor ${ }^{2}$ \\ 1Department of Business Administration, Nile University of Nigeria, Abuja \\ 2Department of Business Administration, Nile University of Nigeria, Abuja
}

*Corresponding Author: Umar Abbas Ibrahim, PhD, Department of Business Administration, Nile Universityof Nigeria, Abuja

\begin{abstract}
The study evaluated whether the use of Artificial Intelligence (AI) in the banking system serves as a useful tool in decision making for the Central Bank of Nigeria (CBN). This research used descriptive survey involving the administration of structured questionnaire on five-point likert scale to a sample size of 160 respondents purposively drawn from a total population of 322 staff from Statistics, Research and Consumer Protection Departments of the Central Bank of Nigeria. Cronbach Alpha Co-efficient $(\alpha)$ was used to test the reliability of the study instrument in which the instrument was found to be highly reliable given a Cronbach score of 0.891 or $89 \%$. A correlational design was used to test the relationships between the attributes of the dependent and independent variables using Pearson's Product Moment Correlation Co-efficient $(r)$ to test the three directional null hypotheses formulated. The results found strong positive significant correlation between the use of Artificial Intelligence to generate Dispense Error data by banks, delay in terms of data received from five commercial banks in Abuja, data integrity on consumer protection and the decision-making of Central Bank of Nigeria. The study recommends a holistic introduction of AI as major service-deliveryenabler by all banks in Nigeria, which will enhance the quality of decision-making of the CBN.
\end{abstract}

Keywords: Artificial Intelligence, Automation, Banking, Decision Making, and Internet Service

\section{INTRODUCTION}

Artificial Intelligence (AI) has been on the springboard of research since the 1940s and often applied to the study of the design of intelligent agents. There have been several types of AI developed over the years, which has been applied to critical decisions in both the private and public sector organizations such as Central Bank of Nigeria, Nigeria Securities and Exchange Commission and other large scale organisations. In the field of decision science, AI is described as the science of making machines smart (Borgesius, 2018). This concept suggests something very unique to the analysis and interpretation of the term AI. Because of the nature of human infallibilities and his susceptibility to natural errors, omissions, and his inability to cope with large volume of data storage in his brain, the emergence of smart machine to handle complex managerial data information becomes obvious. The AI development is a focal point to explain how limited human intelligence and capabilities are to address large and complex decisions in a given situation. AI is an efficient and fast way of using a machine aided device in collecting information, which can be used to understand concepts, policies or resources at a faster rate. The invention of the AI tool has also created and developed tools to collect reliable data, ensuring that no data is lost and producing this data in an efficient manner, which leads to accurate decision making.

According to Utam and Onwe (2012) cited in Ukpata, (2013), a decision can be defined as an action to be selected according to some pre-specified rule or strategy, out of several available alternatives, to facilitate a future course of action. This concept suggests that there are several alternative courses of action available, which cannot be pursued at the same time. As a the process of selecting the best out of several alternatives, decision making is an important tool in determining the creation of policies in theregulatory body like the Central Bank of Nigeria (CBN). As an Apex Bank, it takes critical decisions on the business operations of all the financial institutions within its jurisdiction. Such decisions are usually released in form of policy documents on the conduct of the activities of financial 
institutions within the country. How these decisions are conceptualized and enforced have direct implications on the health and viability of the financial system. Decisions that have been made over time are empirically and practically generated by human efforts which are susceptible to high chances of error that could either lead to loss of human and material resources or a temporal or even permanent business failure. Therefore, the emergence of Artificial Intelligence (AI) as a viable tool for decision making in key business operations and managerial activities becomes critical and fundamental.

\subsection{Statement of the Problem}

Over the years, increase the use of decision support systems, information and communication technologies (ICT) as major financial service delivery enabler, and the jet speed for the digitalization of the financial market globally have brought about the need for rethinking the general philosophy of the banking services for more efficient and timely service delivery to customers.

This also has direct implication on the need for reshaping the way policies are created by the Central Bank of Nigeria in using Artificial Intelligence (AI) to make critical decisions regarding overall banking supervision and control quality. A lot of organizations are seeing the benefits of AI algorithm in picking up big and bite sized data all over the world. According to Tata Consultancy Services (TCS) research, "banking and FS executives found that investment in AI was beneficial in the reduction of production cost by $13 \%$. The typical structure of a decision system is presented in figure 1 below.

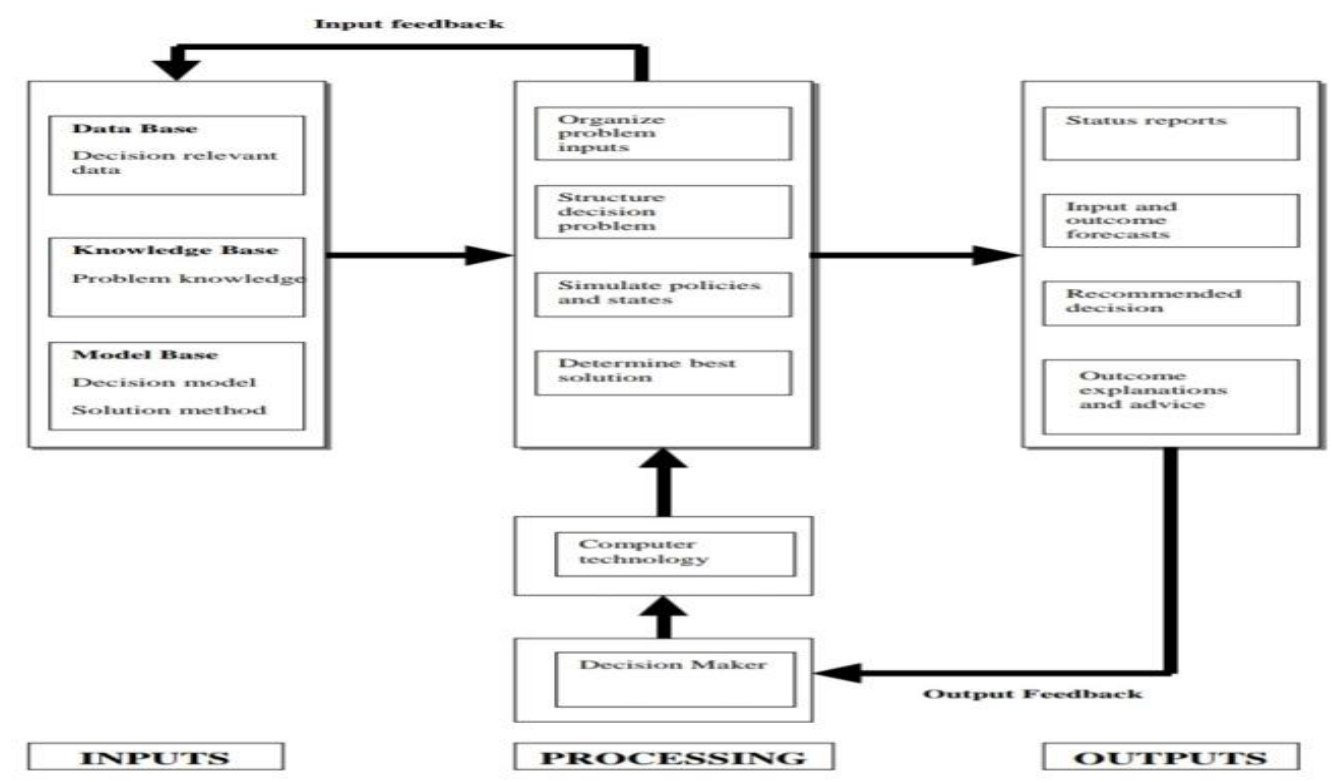

Fig1. Structure of a decision system (Adopted from Phillips-Wren et al.2009)

To achieve such objectives of the CBN, this study is confronted with the problem of effectiveness in the method of collecting dispense error data from consumers, secondly the time lag in receipt of relevant data to guide the formulation of appropriate consumer protection policies by CBN and Thirdly, the unreliability of data integrity report submitted by banks to CBN.

\subsection{Objective of the Study}

The broad objective of the study is to evaluate whether the use of artificial intelligence in the banking system will serve as useful tool for decision making by the Central Bank of Nigeria.

a) To determine the relationship between $\mathrm{AI}$ and decision making on generating dispense error data from consumers

b) To ascertain the extent to which the relationship between AI and decision making in eliminating delay from the receipt of relevant data and formulation of appropriate Consumer Protection Policies in the CBN.

c) To assess the relationship between AI and decision making on data integrity submitted by banks. 


\subsection{Hypotheses of the Study}

The study is based on the formulated hypotheses as follows:

$\mathbf{H}_{01}$ : There is no significant relationship between the use of Artificial Intelligence and decisionmaking on generating dispense error data from consumers in the CBN.

$\mathbf{H}_{\mathbf{0 2}}$ : There is no significant relationship between the use of Artificial Intelligence and decisionmaking on delay in terms of data received from the banks.

$\mathbf{H}_{03}$ : There is no significant relationship between the use of Artificial Intelligence and decisionmaking on data integrity submitted by the commercial banks in Nigeria

\section{LITERATURE REVIEW}

\subsection{Concept of Artificial Intelligence}

McKinsey (2017) pointedly described AI as, the intelligence exhibited by machines and systems, with machines mimicking functions typically associated with human cognition. According to him the operations of the AI has three basic levels which includes, (1) the Lower level, which is the narrow AI, (2) the general level AI/human -level AI and (3) the Super AI. McKinsey (2017) sees the Lowerlevel or narrow AI as the traditionally designed human level of activity which is at present being automated by the state-of-the-art prevailing software which now outperforms the human abilities and competences in a more efficient and enduring specialized area. This according to him will take the forecasting of weather, predicting sales performance, playing board games, as well as the classification of Autonomous driving as a narrow AI which in themselves are performed with significant higher complexity of operation than the current available applications. While the General AI or Human-level AI is underlying sensitivity of the machine to clearly and distinctly understand their operating environment, reasoned and act accordingly as though as humans would act in all dimensions and ramifications. This is known as the machine imitation of human brain. This operation includes both areas such as scientific creativity, general knowledge and social skills. (McKinsey 2017). The Super AI as the third level, is described as the highest level of AI. It is also assessed that at this Super Level AI, the machine is capable of making critical deductions about the unknown environments. This being the case however, there is a growing debate surrounding the uncertainty of whether and how this state can be reached what the implications of what this would be to human living environment as a whole. In the opinions of the Royal Society (2017), Borgesius (2018), Artificial intelligence (AI) is, considered loosely speaking, as, "the science of making machines smart". More formally, AI concerns "the study of the design of intelligent agents." In this context, an agent is "something that acts", such as a computer (Russell and Norvig, 2016).

\subsubsection{Decision Making}

Decision-making is one the primary responsibility for being a manager. The quality of a manager's decision is important for two principal reasons. First, the quality of a manager's decision directly affects his or her career opportunities, rewards, and job satisfactions. Secondly managerial decisions contribute to the success or failure of an organization. (Kreitner and Kinicki 2004). The term, decision-making entails identifying, and choosing alternative solutions that lead to a desired state of affairs. The process begins with a problem and ends when a solution has been chosen. To gain an understanding of how managers can make better decisions and having examined the theoretical models for decision making earlier in our theoretical foundation, we shall focus on (1) the Dynamics of decision making (2) good decision making and (3) creativity in decision-making.

\subsubsection{Dynamics of Decision-Making}

Decision-making is part science and part art. This study examines three dynamics of decision-making. These are knowledge management, decision-making styles and the problem of escalation of commitment - that affect the science component. An understanding of these dynamics can help managers make better decisions. According to Kreitner and Kinicki (2004), the term knowledge management is the development of tools, processes, systems, structures, and cultures explicitly to improve the creation, sharing and use of knowledge critical for decision-making. The effective use of knowledge management helps organizations to improve the quality of their decision making and correspondingly reduce costs and increase efficiency. In same vein, decision-making styles reflect the combination of how an individual perceives and comprehends information and the general manner in 
which they chose to respond to such information. On the other hand, escalation of commitment refers to the tendency to stick to an ineffective course of action when it is unlikely that a bad situation can be reversed. Personal examples include investing money into an old or broken car or waiting for an extremely long time for a bus to take you somewhere when you could have walked just as easily (Kreitner and Kinicki 2004). Such scenario abound often time in the banking system when there is incessant public outcry against certain Bankers' Tariffs that have to do with the spade of charges collected from consumers of electronic banking services and if the Central Bank of Nigeria does not collect reliable data and revise or amend its policy, there is the tendency for the public confidence towards consumer protection policies to be eroded.

\subsubsection{Decision of Consumer Protection}

The propensity of the CBN to manage consumers' complaints on all categories of electronic banking products has greater influence on the behavior of the general public towards the use of such electronic banking products and being included financially. A comparative analysis of such activities carried out by the CBN during the 2014 and 2015 operational periods is as presented on table 1 below:

Table1. Central Bank of Nigeria Complaints Management Activities

\begin{tabular}{|l|l|l|l|l|l|}
\hline $\mathrm{S} / \mathrm{N}$ & Description & $1^{\text {st }}$ Half 2015 & $2^{\text {nd }}$ Half 2-14 & Difference & $\%$ \\
\hline $\mathbf{1}$ & Number of complaints received & 747 & 782 & -35 & $(4.48)$ \\
\hline $\mathbf{2}$ & Number of complaints resolved/closed & 481 & 504 & -23 & $(4.56)$ \\
\hline $\mathbf{3}$ & Amount claimed (\#' Billion) & 8.09 & 15.67 & $(7.58)$ & $(48.37)$ \\
\hline $\mathbf{4}$ & Amount refunded (N' Billion) & 1.87 & 2.38 & $(0.51)$ & $(21.46)$ \\
\hline $\mathbf{5}$ & Amount claimed (US\$) & $751,744.26$ & $1,505,552.09$ & $(753,807.83)$ & $(50.07)$ \\
\hline $\mathbf{6}$ & Amount refunded (US\$) & $963,920.05$ & $901,864.19$ & $62,055.86$ & 6.88 \\
\hline
\end{tabular}

Note: The amount includes complaints from previous periods that were resolved during the reporting period

Source: Central Bank of Nigeria Financial Stability Report (2015)

From the table 1 above, a total of 747 complaints involving the sums of $\$ 8.09$ billion and US $\$ 751,744.26$ were received in the review period. Also, during the period, a total of 481 cases, including some outstanding cases from previous periods were resolved or closed. The refunds effected with respect to these cases amounting to $\$ 1.87$ billionand US\$963,920.05 were made to customers. The value of cumulative claims by complainants against banks and other financial institutions (OFIs) amounted to $\$ 8.09$ billion, while cumulative refunds to complainants totaled $\$ 2.38$ billion, US\$957,920.00 and GB6, 0000.00 pounds. (CBN FSR, 2015). In comparison to the second half of 2014 , the number of complaints received reflected a decrease of 35 or 4.48 per cent. Also, the number of resolved/closed complaints decreased by 23 or, 4.56 per cent. Similarly, cumulative claims by complainants in the review period decrease by 7.58 billion or, 48.37 per cent compared with the second half of 2014; While refunds by the commercial banks to complainants declined by 510.37 million or, 21.46 per cent. (CBN FSR, 2015). The comparative analysis however, does not provide explanation as to whether the decline in the variables were associated with improvement in banks' use of innovative technology to track and handle consumers' complaints effectively and promptly or were occasioned by banks' inability to handle consumers' dispense error complaints adequately thereby leading to lack of consumers' confidence on the financial system thereby discouraging them to lay further complaint as data on opinion pools from the consumers were not made available in the report.

\subsection{Theoretical Framework}

This study employed two theories with other interlocking theories that provide critical support for our theoretical and empirical constructs of the study. The two major theories include:

The Modern sequential decision theory as developed by Alan S. Mann (1960), which is an algorithmic operation that is very popularly applied in the field of artificial intelligence. The tenet of the theory holds, that take the dynamics of the universe is fussed into the basic operation and consideration thereby the parts of the problem are delayed until it must be solved. This model can be assumed as a procedural approach to basic fundamental tenets of decision-making or as a step by step operation to decision theory. Sequential decision- making has as a consequence the intertemporal choice problem, where earlier decisions can directly affect or influences the later available choices (Ramsey, 1960). In general, researches in decision-theoretic planning and learning mostly 
focus largely on a single-objective setting. Sequential decision-making problems emerge with multiple objectives which arise naturally to address the complexity of issues of multiple objectives that hold sway on one single line of system whole. This tends to eliminate the unique nature of challenges emanating from the dynamics of the system complexity in decision analysis. (Roijers, 2013).

Also, the Rational Choice Model or sometimes referred to as rational action theory is relevant for understanding and often formally modelling social and economic behavior. According to Becker (1976), the basic assumption of rational choice theory is that aggregate social behavior results from the behavior of individual actors, each of whom is making their individual decisions. The theory presupposes that managers use a rational, four-step sequence when making decisions: (1) identify problem (2) generating alternative solutions, (3) selecting a solution, (4) implementing and evaluating the solution. According to this theory Managers are completely objective and possess complete information to make a decision. Despite the criticism of being unrealistic, the rational model has been quite instructive because it analytically breaks down the decision-making process and serves as a conceptual anchor for newer models. Rational choice theory in effect assumes that the individual decision-makers ordinarily has a given preferences among the available choice alternatives that allow them to state which option they prefer. These preferences are generally assumed to be in the normal situation complete in themselves. The person can therefore always say which of two alternatives they consider preferable or that neither is preferred to the other. Lau (2003) posits that, if the theory considers uncertainty, it has an "expected value" framework. This also implies that the approach holds that decision-makers should gather sufficient information about every plausible course of action to evaluate it. Therefore, it presupposes that every consequence or outcome associated with each alternative is assumed to a certain fixed value for the decision-maker.

\subsubsection{Justification for theoretical base}

The modern sequential decision theory is one of the decision theories being largely applied in the study of Artificial Intelligence due to its ability to address complex organizational problems with unique multiple objectives. Similarly, the Rational Choice Economic theory is a basic economic theory used profoundly to address political, economic and social issues that directly link individual behavioral patterns that serve as major determinants for their individualistic and or group decisionmaking within the organizational settings and the society at large. These two theories provide interlocking and disposition in explaining our present context. Similarly, the theories are symbiotic and mutually reinforcing in the debate surrounding the concept of "Artificial Intelligence as a tool for decision-making in a given organizational context.

\subsection{Empirical Review}

Several studies relating to the phenomena within the study environment as well as across international frontier were reviewed. For instance, Castelli, Manzoni and Popovic (2016) conducted an empirical research on "An Artificial Intelligence System to Predict Quality of Service in Banking Organizations, carried out in Portugal. They adopted a review of an analytical model that can predict the service quality of banking system using AI. They used historical data related to transactions of several banks and found that while the traditional banking service system relies on theories and assumptions about a problem at hand, they lacked the scientific means of solving such problems. Therefore, they proposed the use of AI as learning model to address problem from actual data generated. However, the gap in their study was the inability to clearly define the scope of the study, and non-inclusion of customers' survey to determine the service quality of the banks using AI application.

Bakpo and Kabari, (2018) also conducted a research on "credit risk evaluation system: an artificial neural network approach" where they built classification rules that properly assess bank customers as good or bad. They proposed the use of theory of artificial neural networks and business rules to correctly determine whether a customer is good or bad. To avoid redundancy, different attributes are taken into consideration during each phase of classification. The proposed approach allows for using different rules within the same data set, and for defining more accurately clients with high risk. Their result indicates that the model presented is promising and reasonable. The gap in their study and result indicated a cursory approach that does not provide clear framework for application of the model and no define population and scope was stated in the study. According to Pomerol and Adam (2008), 
reasoning and recognition are key poles in decision making that are closely linked. A good decision stems from human cognitive reasoning that weighs alternatives and selects a decision based on a criterion.

\section{Methodology}

A correlational design was used to test the relationships between the attributes of the dependent and independent variables. Due to the nature and scope of this study, the researcher selected 160 respondents purposively from a total population of 322 staff of Statistics, Consumer Protection and Research Departments of the Central Bank of Nigeria, Abuja. This represents 49.7 or $50 \%$ of the study population, which is considered highly adequate above the international bench- mark of representative sample of $10 \%$.

Data for this study were primary data collected through the use of a structured questionnaire designed on Five-point Likert Scale, which reflected detailed dimensions of the hypothesized variables of the study. The questionnaires were administered randomly to the study population. The study instrument was given to research experts in Management Science field and statisticians in Central Bank of Nigeria who made relevant critiquing of the instrument and their observations and criticisms noted and the instrument amended accordingly. This confirms its face-validity of being able to measure what it ought to measure theoretically and empirically. Thereafter a reliability test was conducted using Alpha Cronbach Co-efficient reliability test. The result is presented in table 2 below:

Table2. Reliability of Measures of Artificial Intelligence and Decision-Making

\begin{tabular}{|l|l|l|}
\hline Variables & Cronbach's Alpha & No of Items \\
\hline AI to Generate Dispense Error information & 0.723 & 3 \\
\hline AI to eliminate delay in time of the receipt of relevant data & 0.770 & 3 \\
\hline AI use of data integrity submitted by banks & 0.812 & 3 \\
\hline Decision-making by CBN & 0.826 & 4 \\
\hline Overall Cronbach's Alpha & 0.891 & 13 \\
\hline
\end{tabular}

Source: Computed from Field survey 2019 by the authors using SPSS Version 23.02019

From Table 2 above, the reliability test revealed a Cronbach Alpha Co-efficient result of 0.891 or $89 \%$.

\subsection{Model Specification}

The PPMCC Statistical formula used in the analysis of our field data is given below:

$$
r=\frac{n\left(\sum x y\right)-\left(\sum x\right)\left(\sum y\right)}{\sqrt{\left[n\left(\sum x^{2}\right)-\left(\sum x\right)^{2}\right]\left[n\left(\sum y^{2}\right)-\left(\sum y\right)^{2}\right]}}
$$

Where:

$\begin{array}{lll}r & = & \text { Pearson product Moment Correlation } \\ \mathrm{n} & = & \text { number of pairs of scores } \\ \Sigma \mathrm{xy} & = & \text { sum of the products of paired scores } \\ \Sigma \mathrm{x} & = & \text { sum of } \mathrm{x} \text { scores } \\ \Sigma \mathrm{y} & = & \text { sum of } \mathrm{y} \text { score } \\ \Sigma \mathrm{x}^{2} & = & \text { sum of squared } \mathrm{x} \text { scores } \\ \Sigma \mathrm{y}^{2} & = & \text { sum of squared } \mathrm{y} \text { scores }\end{array}$

Decision Rule: In all cases the general rule holds that, we reject the Null Hypothesis if p-value is less than 0.05 $(\mathrm{p}<0.05)$ and accept Null Hypothesis if $\mathrm{p}$-value is greater than $0.05(\mathrm{p}>0.05)$.

The data obtained from the respondents were analysed with the use of descriptive statistics and parametric test statistical tools such as standard deviation for the analysis of question items in the study questionnaire while the Pearson Product Moment Correlation $(r)$ was used to test the research hypotheses. 


\subsection{Results and Analysis}

Table3. Questionnaire Returned Rate

\begin{tabular}{|l|l|l|}
\hline Questionnaire & Number & Percent (\%) \\
\hline Total number administered & 160 & 100 \\
\hline Returned & 152 & 95 \\
\hline Unreturned & 8 & 5 \\
\hline
\end{tabular}

Source: Field Survey, 2019.

Table 3 shows that out of 160 questionnaires administered to respondents, 152 representing 95\% were duly completed and returned while 8 representing $5 \%$ were not returned.

\subsubsection{Descriptive Statistics}

Table4. The Descriptive Analysis of the Questionnaire

\begin{tabular}{|c|c|c|c|c|c|}
\hline & $\mathbf{N}$ & Minimum & Maximum & Mean & $\begin{array}{l}\text { Std. } \\
\text { Deviation }\end{array}$ \\
\hline Gender: & 152 & 1 & 3 & 1.13 & .363 \\
\hline Females & 152 & 1 & 2 & 1.18 & .384 \\
\hline $\begin{array}{l}\text { Years of Experience: } \\
\qquad 1-10 \text { years }\end{array}$ & 152 & 1 & 7 & 4.94 & 1.390 \\
\hline $11-20$ year & 152 & 1 & 2 & 1.27 & .447 \\
\hline 21 years and above & 152 & 1 & 6 & 2.14 & 1.374 \\
\hline Employment Status: Officers & 152 & 1 & 5 & 3.87 & .878 \\
\hline Middle Managers & 152 & 1 & 2 & 1.20 & .404 \\
\hline $\begin{array}{c}\text { Senior Managers } \\
\end{array}$ & 152 & 1 & 9 & 3.67 & 2.570 \\
\hline $\begin{array}{l}\text { Whether there is significant correlation } \\
\text { between the use of Artificial Intelligence } \\
\text { and CBN decision-making on generating } \\
\text { distance Error data from consumers }\end{array}$ & 152 & 1 & 6 & 3.02 & 1.571 \\
\hline $\begin{array}{l}\text { Use of AI will produce a better Dispense Error } \\
\text { Data than the current internet platforms of } \\
\text { Banks most Banks' customers give misleading } \\
\text { information on Dispense Error platform }\end{array}$ & 152 & 1 & 5 & 2.09 & .682 \\
\hline $\begin{array}{l}\text { Whether there is significant correlation } \\
\text { between the use of AI and CBN decision- } \\
\text { making on delay in terms of data received } \\
\text { from banks. }\end{array}$ & 152 & 1 & 3 & 1.95 & .444 \\
\hline $\begin{array}{l}\text { Data generated by banks on internet banking } \\
\text { products are not timely enough to enhance } \\
\text { CBN decision-making }\end{array}$ & 152 & 1 & 5 & 2.01 & .513 \\
\hline $\begin{array}{l}\text { The use of AI will enhance timely receipt of } \\
\text { information from banks by CBN }\end{array}$ & 152 & 1 & 5 & 1.92 & .643 \\
\hline $\begin{array}{l}\text { Whether there is significant correlation } \\
\text { between the use AI and CBN decision- } \\
\text { making on data integrity submitted by banks }\end{array}$ & 152 & 1 & 7 & 1.85 & 1.353 \\
\hline $\begin{array}{l}\text { Data generated from the bank are quite reliable } \\
\text { and meet CBN standards for policy making }\end{array}$ & 152 & 1 & 5 & 1.39 & .851 \\
\hline $\begin{array}{l}\text { Consumers" interests will be more protected if } \\
\text { AI is used. }\end{array}$ & 152 & 1 & 5 & 1.90 & .978 \\
\hline $\begin{array}{l}\text { Implications of the use of Artificial } \\
\text { Intelligence on Decision Making by Central } \\
\text { Bank of Nigeria }\end{array}$ & 152 & 1 & 3 & 1.19 & .443 \\
\hline $\begin{array}{l}\text { There is no correlation on the use of AI and } \\
\text { decision-making }\end{array}$ & 152 & 1 & 8 & 3.27 & 1.900 \\
\hline $\begin{array}{l}\text { There is correlation on the use of AI and } \\
\text { decision-making }\end{array}$ & 152 & 1 & 4 & 1.97 & 2.455 \\
\hline Valid N (listwise) & 152 & & & & \\
\hline
\end{tabular}

Source: Researcher's Field Survey, 2019 computed from SPSS Version 23.02019 
From the comparative descriptive analysis of the results presented on table 4 above, the demographic information of the respondents showed that, both males and female are almost equal with Mean value and std. deviation Males of 1.13.and .363 while females were 1.18 and .384 respectively. Out of which their years of experience in banking services stood at $1-10$ years, $11-20$ years and 21 years and above with Mean values and Std. of 4.94, 1.27, 2.14 and 1.390, .447 and 1.374 respectively. This indicates that more of the respondents were within the years of experience of 21 and above. Similarly, with the rank of the respondents, results showed that Officers, Middle Managers and Senior Managers have Mean values and Std. of 3. The results showed lower mean values of 3.87, 3.67 and Std. of .878 and 2.570 respectively, indicating that most of the respondents were within the rank of Middle level Managers showing that their responses could be attached with high level of credibility due to their levels or ranks in banking operations. Furthermore, respondents were asked relevant questions or to express opinions in all the relevant dimensions and parameters regarding the hypothesized variables of our study, and their views are covered appropriately as presented in the Descriptive statistics table give

\subsubsection{Testing of Hypothesis}

$\mathbf{H}_{\mathbf{0}} .1$ : There is no significant correlation between the use of Artificial Intelligence to generate dispense error data from consumers and decision making by CBN. On the first hypothesis, the correlation analysis in table 5 below shows a very high positive significance value (r-value) of $0.928^{* *}$ and probability value (p-value) of 0.000 . This analysis results fails to support the acceptance of null hypothesis since the $\mathrm{p}$-value is less than $0.05(\mathrm{p}=0.000<0.05)$ significance value ( $\mathrm{r}$-value) and therefore we support the acceptance of alternative hypothesis. This implies that there is significant correlation between the use of Artificial Intelligence to generate dispense error data from consumers and the decision making by CBN.

Hypothesis Two: $\boldsymbol{H}_{0} .2$ : There is no significant correlation between the use of Artificial Intelligence to eliminate delay in time of the receipt of relevant data and formulation of appropriate consumer protection policies by CBN. For second hypothesis, the correlation analysis in the table 5 table gives a high positive significance value (r-value) of $0.761^{* *}$ and a probability value ( $\mathrm{p}$-value) of 0.000 . Thus, because the $\mathrm{p}$-value is less than $0.05(\mathrm{p}=0.000<0.05) \mathrm{r}$-value we therefore reject the null hypothesis and the alternative hypothesis is accepted. This signifies that, there is significant correlation between the use of Artificial Intelligence to eliminate delay in time of the receipt of relevant data and formulation of appropriate consumer protection policies by CBN.

Hypothesis Three: $\mathbf{H}_{\mathbf{0}} .3$ : There is no significant correlation between the use of Artificial Intelligence and data integrity submitted by banks for decision-making by CBN. For third hypothesis, the correlation analysis in the table 4 above gives a high positive significance value (r-value) of $0.842^{* *}$ and a probability value (p-value) of 0.003 . Since the $p$-value is less than $0.05(\mathrm{p}=0.003<0.05) \mathrm{r}$ value Therefore, the null hypothesis is rejected, and the alternative hypothesis is accepted. This implies that, there is a significant correlation between the use of Artificial Intelligence and data integrity submitted by banks for decision-making by CBN.

Table5. Pearson's Correlation Results

\begin{tabular}{|c|c|c|c|c|c|}
\hline & & $\begin{array}{l}\text { Decision- } \\
\text { making } \\
\text { by CBN }\end{array}$ & $\begin{array}{l}\text { AI to } \\
\text { Generate } \\
\text { Dispense } \\
\text { Error } \\
\text { information }\end{array}$ & $\begin{array}{l}\text { AI to eliminate } \\
\text { delay in time of } \\
\text { the receipt of } \\
\text { relevant data }\end{array}$ & $\begin{array}{l}\text { AI use of data } \\
\text { integrity submitted } \\
\text { by banks }\end{array}$ \\
\hline \multirow{3}{*}{$\begin{array}{l}\text { Decision- } \\
\text { making by } \\
\text { CBN }\end{array}$} & Pearson Correlation & 1 & $.928^{* *}$ & $.761^{* * *}$ & $.842^{* *}$ \\
\hline & Sig. (2-tailed) & & .000 & .039 & .000 \\
\hline & $\mathrm{N}$ & 152 & 152 & 152 & 152 \\
\hline \multirow{3}{*}{$\begin{array}{l}\text { AI to } \\
\text { Generate } \\
\text { Dispense } \\
\text { Error } \\
\text { information }\end{array}$} & Pearson Correlation & $.928^{* * *}$ & 1 & .000 & $.454^{* * *}$ \\
\hline & Sig. (2-tailed) & .000 & & .998 & .000 \\
\hline & $\mathrm{N}$ & 152 & 152 & 152 & 152 \\
\hline \multirow{3}{*}{$\begin{array}{l}\text { AI to } \\
\text { eliminate } \\
\text { delay in } \\
\text { time of the } \\
\text { receipt of } \\
\text { relevant } \\
\text { data }\end{array}$} & Pearson Correlation & $.761^{* * * *}$ & $.451^{* * *}$ & 1 & $.762^{* * *}$ \\
\hline & Sig. (2-tailed) & .000 & .000 & .010 & .000 \\
\hline & $\mathrm{N}$ & 152 & 152 & 152 & 152 \\
\hline
\end{tabular}




\begin{tabular}{|l|l|l|l|l|l|}
\hline \multirow{2}{*}{$\begin{array}{l}\text { AI use of } \\
\text { data }\end{array}$} & Pearson Correlation &. $.842^{* * *}$ & $.454^{* *}$ & .148 & 1 \\
\cline { 2 - 6 } $\begin{array}{l}\text { integrity } \\
\text { submitted } \\
\text { by banks }\end{array}$ & Sig. (2-tailed) & .000 & .000 & .151 & .000 \\
\cline { 2 - 6 } & $\mathrm{N}$ & 152 & 152 & 152 & 152 \\
\hline
\end{tabular}

**. Correlation is significant at the 0.01 level (2-tailed).

*. Correlation is significant at the 0.05 level (2-tailed).

Source: Researcher's Field Survey, 2019 using SPSS Version 23.0, 2019.

\section{DISCUSSION OF FINDINGS}

From the critical questions of trying to know whether there is significant correlation between the use of Artificial Intelligence and the Central Bank of Nigeria (CBN) decision-making on generating distance Error data from consumers, the result shows that $82 \%$ of the respondents strongly agreed that the use of AI will produce a better Dispense Error Data than the current internet platforms of Banks. Sixty-three percent agreed that Banks' customers give misleading information on Dispense Error internet platforms of banks. This is in agreement with the view of McKinsey (2017) who perceived that AI is a key driver for business automation. In support of this, Ogwuma (1997) posits that, "as Nigerian banks intensify efforts to enhance, their banking technology and capability, there is need for proper, phased and coordinated implementation of automation shames." This will definitely displaced errors emanating from systems upgrades as the existing one get older soon with the advent of new models coming from the west. Fifty-five percent of the respondents strongly agreed that data generated by banks on internet banking products are not timely enough to enhance CBN decisionmaking. While $70 \%$ of the respondents agreed that the use of AI will enhance timely receipt of information from banks by $\mathrm{CBN}$ and subsequently enhance CBN quality of decision-making on Banks' internet products. Further to this position, in the respondents' opinions as to whether there is significant correlation between the use $\mathrm{AI}$ and $\mathrm{CBN}$ decision-making on data integrity submitted by banks, 55\% strongly disagreed on "Data generated from the bank are quite reliable and meet CBN standards for policy making." That most data generated are not reliable due to many incorrect information given by customers. Hence $60 \%$ strongly agreed that the Consumers' interests will be more protected if AI is used. This is in line with the view of Egbuna (2008) that active consumerism generates creative banking products and services which are needed to keep up with the expectations of the customers and inherently contributes towards improved banking products and services.

\section{CONCLUSION AND RECOMMENDATIONS}

\subsection{Conclusion}

From the empirical analysis of the research, it is an irrefutable fact that quite a number of complaints presented by customers against internet services products are not being properly generated and censored by most banking institutions. This often gives misleading information to the Central Bank Department of Consumer Protection and the Department of Fraud Investigation. It is equally established by the findings of this study that, in order to have a robust quality and quantity of decision-making in terms of handling commercial banks' complaints timely for their customers, the application of Artificial Intelligence (AI) to drive the business of the banking industry in Nigeria is very important. This will reduce other operational risks associated with just mere computerization, and automation of few banking services. As Alyssa (2019) coined it, "Artificial intelligence in finance is transforming the way we interact with money. AI is helping the financial industry to streamline and optimize processes ranging from credit decisions to quantitative trading and financial risk management." Therefore, introduction of AI should be holistic.

\subsection{Recommendations}

Based on the findings of this research, the following recommendations are proposed:

1. Dispense Error platforms of banks should be upgraded using AI coded platform that would link up the customer's complaint directly to the bank and simultaneously to the CBN within few minutes

2. In order to have user friendly and timely response to customers' complainants, the CBN should regulate banking internet products by direct link to each customer of any bank without reference to the bank concerned. This will help to strengthen CBN policy and regulation of banking operations generally.

3. The Central bank should make the redeployment of AI for service delivery by all banks in Nigeria mandatory just as the minimum capital based is regulated by it. 


\section{FUtURE RESEARCH}

Arising from the results of this study, the following areas are recommended for future research:

1. Implications of expenditure on the introduction of Artificial Intelligence Architectures on banking operations in Nigeria.

2. The role of banks' Artificial Intelligence Architectures on Nigerian Economic Growth

\section{REFERENCES}

[1] Alan, S. (1960). Linear Programming and sequential decisions. Management Archive, Vol. 6, No. 3. Pp. 259-267.Manne Cowells Foundation, Yale University.

[2] Alyssa, S. (2019). AIand the Bottom Line: 15 Examples of Artificial Intelligence In Finance. www.builtin.com/artificial intelligence

[3] Becker, G. S. (1976). The Economic Approach to Human Behavior. Chicago. Description and Scroll to chapter-preview links.www.//books.goggle.com

[4] Borgesius, F. Z. (2018). Discrimination, artificial intelligence, and algorithmic decision-making

[5] Bakpo, F. S. and Kabari, L. G. (2008). Credit Risk Evaluation System: An Artificial Neural Network Approach. Nigerian Journal of Technology, Vol. 28 No.1

[6] Central Bank of Nigeria (CBN). Financial Stability Report (2015). June 2015 CBN, Half year Report

[7] Castelli, M., Manzoni, L. and Popovic A. (2016). "An Artificial Intelligence System to Predict Quality of Service in Banking Organizations. Computational intelligence and Neuroscience.Vol.2016. Hindawi Publishing Corporation

[8] Egbuna, N. (2008). Consumer Protection and Financial Stability in Malaysia: Lessons for Nigeria. Central Bank of Nigeria, Bullion Publication. Vol. 32 No.3

[9] Kreitner, R., and Kinicki, A. (2004). Organizational Behaviour, (6 ${ }^{\text {th }}$ Ed.). McGraw - Hill/Irwin, a business wing of McGraw - Hill Company Inc. NY. USA.

[10] Lau, R.R. (2003): Theoretical Approaches - Models of Decision https://psycnet.apa.org/record/200388243-002

[11] McKinsey, C. (2017). Artificial Intelligence - Automative's new value-creating engine, McKinsey Center for Future Mobility.

[12] Ogwuma, P. A. (1997). The future role of technology in banking development in Nigeria. Central Bank of Nigeria, Bullion Publication. Vol. 21 No.4.

[13] Pomerol JC and Adam F 2008 Understanding human decision making- A fundamental step towards effective intelligent decision support In Intelligent Decision Making: An AI Based Approach (ed. PhilipsWren G, Ichalkrange $\mathrm{N}$ and Jain L) Springer Berlin pp.3-40.

[14] Ramsey, William M., 1960-. Cambridge, UK: Cambridge University Press. p. 337. www.worldcat, org ISBN 9780521871426. OCLC 865297798.

[15] Russell, S.J and Norvig P, (2016). Artificial intelligence: a modern approach (third edition) (Prentice Hall 2016)

[16] Royal Society (UK). (2017). 'Machine learning: the power and promise of computers that learn by example' (April 2017) https://royalsociety.org/ /media/policy/projects/machine-learning/publications/ machine- learningreport.pdf accessed 1 May 2017.

[17] Roijers, D. M. (2013) A survey of multi-objective sequential decision-making.

[18] Ukpata, S. I. (2013). Network analysis as tool for effective project management: A study of the Nigerian Communications Commission (NCC).

Citation: Umar Abbas Ibrahim, PhD, Chinyere Jane Nwobilor. "Artificial Intelligence as a Tool for Decision Making: A Perspective from the Central Bank of Nigeria" International Journal of Managerial Studies and Research (IJMSR), vol 8, no. 1, 2020, pp. 76-85. doi: http:// dx.doi.org/10.20431/23490349.0801008 .

Copyright: (1) 2020 Authors. This is an open-access article distributed under the terms of the Creative Commons Attribution License, which permits unrestricted use, distribution, and reproduction in any medium, provided the original author and source are credited. 